\title{
Training Modules for Improved Storage Techniques to Reduce Post-harvest Losses of Maize in Ghana, Work in Progress
}

\section{Ms. Hallie E Supak, Texas A\&M University}

I am a senior undergraduate student at Texas A\&M University studying Biological and Agricultural Engineering. I have been working with my partner and co-author Victoria Baltazar since May on this project. We are apart of the Post-Harvest Engineering and Education (PHEED) research group under the supervision of Dr. Janie Moore PhD focusing on post-harvest loss education and improvement in African countries with a special interest in women farmers. This is a topic I am very passionate about and am excited about the opportunity to develop our research further.

\section{Ms. Victoria Baltazar, \\ Janie M Moore, Texas A\&M University}

Dr. Janie McClurkin Moore is an Assistant Professor in the Biological and Agricultural Engineering Department at Texas A\&M University in College Station. A native of Columbus, Ohio, she attended North Carolina A\&T State University where she received a B.S. in Bio Environmental Engineering in 2006. She then began pursuing her graduate education at Purdue University in the Agricultural and Biological Engineering Department, completing her Ph.D. in 2015. Her primary research areas include 1) mycotoxin risk assessment and treatment in stored grains and 2) innovate instructional strategies for Biological and Agricultural Engineering students. 
Training modules for improved storage techniques to reduce post harvest losses of maize in Ghana 


\begin{abstract}
Post-harvest losses (PHL) remain higher in Sub-Saharan Africa than the rest of the world. Even though technology is available, food insecurity persists. Women make up a large portion of the farming workforce yet do not have equal access to resources. Focusing efforts on providing support to women could reduce crop losses.
\end{abstract}

The primary goal of this project is to improve the application of technologies targeting the reduction of postharvest loss in food insecure areas such as Ghana. This work examines a methodology to improve Ghana's food security by providing better resources and more effective training to women in Ghana's agricultural community. Research was conducted on the intersection of Ghana's social and environmental climate and crop storage practices and technologies with a specific focus on the effect of behavioral and gender roles on women in agriculture. From this information, an educational module was designed for the volunteers who would train the farmers on how to improve their storage practices. This module embodied much of the "train the trainer" method which teaches both post harvest strategies alongside teaching and communication strategies. The focus of the module was to provide an accurate context of the social environment and issues the volunteers will need to address while training the farmers. In order to best determine the specific needs of an individual area, a case study will be performed within each community and then the training modules are adjusted based on the results. This will better address issues that may have been ignored in the past due to lack of consideration of cultural and individual differences. By first training the volunteers, the aim is to more effectively communicate the practices and technologies being taught so they will be used long term.

Following this module, interviews with experts in the selected area and a more directed case study on a test population will be conducted to develop a training module to be used by the volunteers. An evaluation of the effectiveness of the module will follow the post-harvest season, as shown in Table 2, that will look at use of technology, crop yield, and personal development. The effectiveness will be measured by comparing the harvest yields from the previous season with the one following the training.

\title{
Background
}

Post Harvest Loss (PHL) is the loss of consumable harvest from the time the crop is harvested to the table. Factors such as pests, rodents, and moisture contribute to these losses at every step of the post-harvest process. PHL is present all around the world with more waste occurring post retail in more developed countries and pre-retail in developing countries. The goal of this project was to focus on how to reduce post harvest losses before retail. When considering the statistics presented by the Food and Agricultural Organization of the United Nations (FAO), Sub Saharan 
Africa has the highest relative amount of PHL at 35\% [1]. Maize alone accounts for $17.8 \%$ losses in the region [2]. The Global Hunger Index (GHI) is a statistic which takes undernourishment, child wasting, child stunting, and child mortality rates in undeveloped countries. Along the SSA

belt, Ghana is one of the few countries that falls into the moderate category, ranking 15.2 out of a possible 100 [3]. This suggests there is enough infrastructure to provide support for a program to reduce post harvest loss. A need for such a program is still necessary though considering they are still lagging globally. Within Ghana, 2.2 million people are severely food insecure, $7.9 \%$ of the population and about 2 million people are vulnerable to food insecurity [4]. Without a goal of aiding to reduce PHL, the idea of reducing this statistic is almost out of reach.

Impacts of Gender

Sub-Saharan Africa has a higher percentage of women involved in agriculture than any other continent; however, women only have a fraction of the resources available to their male counterparts. Generally speaking, $62.3 \%$ of the female population in SSA countries work in agriculture. Within Ghana, that number is roughly $50 \%$. Women are often marginalized when it comes to resources and training. Focusing efforts of providing support and resources to women in agriculture could increase farm yields by $20 \%-30 \%$ [5].

Addressing the gender inequality within the agricultural community is not an isolated issue. There is a complex web of factors that contribute to the success of introducing new technology. For example, it is a common practice that men farm what are considered "cash crops" because they will generate a better income to support the household while women farm subsistence crops. If new PHL technology is brought to the community to support and aid women with subsistence crops and is successfully adopted, it could make said crops more profitable. This could then cause the dynamic of the community to change to men farming the new cash crop and women farming not as profitable crops [6]. This is just one example of how gender relations can become dynamic and how gender equalization efforts can have unexpected downsides.

Other factors such as land ownership, labor availability, and access to outside resources can make implementing new practices difficult [6]. Many countries in Africa have made legislation to support gender equality especially when it comes to land ownership. However, in reality, women still do not have the same land security. Moving forward with this knowledge, third party organizations must adapt their strategies to have a more successful implementation and continued use of the introduced technology.

PHL Technology

During the processing of crops, portions are lost due to interference from pests, rodents, and 
moisture. Technologies and practices have been developed to inhibit the effects of these factors in the drying and storage stages.

Drying is a critical step proceeding storage for any length of time. In order to prevent mold growth, grain must be dried to below $13 \%$ moisture content dry basis for long term storage and $15 \%$ for short term [2]. Traditionally, farmers in Ghana practice drying maize in field, on ground, or on platforms [7]. Leaving crop to dry in the field or on the ground increases exposure to pests and contaminants. More recently, plastic tarps have been used to act as a barrier between the maize and the ground to reduce contaminants from the ground, but this reduction is minor. However, this practice requires constant vigilance should the maize be soaked from rain or targeted by birds. New technology, such as mechanical or solar dryers, could offer improvement and better quality control. The price of these dryers is too costly for a single farm, but could perhaps be funded and used by the community at large [7].

Storage losses account for the largest percent of PHL of maize in Ghana. During the wet season, the main cause is mold and in the dry, insects [2]. Current storage practices range from chemical fumigation to tradition woven bags. Hermetic storage is a method that creates an airtight seal within a container that keeps out moisture and pests. For use in storage, this technology is available in several forms and proven to be effective in various studies [8,9]. In one study, metal silos were shown to be effective in killing all pests within the barrel [10]. The airtight storage creates an anaerobic atmosphere due to the pests and microbes consuming the oxygen. Purdue Improved Cowpea Storage (PICS) bags are another type of hermetic storage that has three layers of plastics that completely seal crops [8]. These technologies are affordable and can easily be available to farmers in the region.

Behavioral Analysis

On the continent where $50 \%$ of fruits and vegetables, $40 \%$ of roots, and $20 \%$ of cereal are lost to inefficient post-harvest practices, all external efforts need to be well calculated and strategized [12]. After many behavioral studies, a few problems stuck out as most impactful. One of the problems was that there was a misalignment of resources and needs when help was funded. The PICS bags gained much interest during trainings, but there was a major problem. The education sessions were done in the offseason, and many farmers would wait until the weeks leading up to the harvest season to purchase any necessary supplies. This gap in time made it hard for the farmers to recall vital information they learned causing them to forget about the bags and other technologies and techniques learned and stick with their old ways [12]. The education sessions would often cover almost a dozen different techniques and technologies which additionally made it difficult to recall any specifics after months of not using any of this education [11]. Another misalignment issue is that the profit the smallholder farmers make in one harvest season is meant 
to last all year. So when the education sessions took place right after the harvest season, farmers had the money, but their minds were not focused on purchasing any harvesting resources. When the time came to buy these supplies later, the farmers were barely scraping by and could no longer afford these valuable bags since they were five times more expensive than their original ones[12].

A behavioral tendency of all humans is to place a bias on short-term thinking over long-term. This psychological inclination determines the outcome of many seemingly harmless choices. This line of thinking is very commonly seen among these SSA farmers. When a technology is proposed, the current benefits are usually prefered over the long term ones [11]. It is difficult for these community members to conceptualize the long term benefit of buying more expensive PICS bags when they appear to look relatively equal to their original ones and when the benefits would not be seen until two or more harvest seasons [12]. A way to demonstrate just how much of a vital impact using hermetic storage is is one of the major keys in helping these smallholder farmers.

Another overlooked source of PHL is due to farmers not utilizing collective storage. Collective storage is a communal storage facility at the disposal of the whole village, and farmers can use them if they opt to join farmers associations for a small fee. These facilities offer protection for the crop and provide resources that aid in selling their cereals more efficiently and communally. However, researchers are finding that these resources are only being used by approximately $20 \%$ of the farming population [12]. This is because many families either choose to sell all their crop all at once or store it at home for consumption and in the hopes of selling at a better price. What was found however, is that the crop was much more likely to go bad when stored in the home, but families still chose to keep with this traditional method because they saw the grains as a type of currency that they can use to barter and trade throughout the year. In their minds, this was a sort of safety net when in reality this method in inefficient and not as cost saving as using collective storage and farmers associations [12]. This is another prime example of the negatives of short-term thinking. Being able to correct these traditional practices will benefit these SSA farmers exponentially.

\section{Methods}

Case Study of community in Ghana

After conducting thorough background research on all aspects of the post-harvest processes in underdeveloped countries, a case study was developed for a sample population of women farmers in Ghana. This case study is centered around a few categories that were deemed vital for determining how to develop the best possible education modules. These categories included 
background information, household information, farming, technologies, and training information. The case study will also act as a pre-evaluation of the effectiveness of the modules to measure self-reported losses. The questions in the survey, as shown in Table 1, will be translated though local volunteers to better suit the understanding of the community. The answers to the case study (Table 1) will either be answered directly through the person being interviewed or be determined through observation and investigation during the interview process (e.g literacy level or financial status). Once the final results of this case study are received, the data is analyzed and classified to determine what issues women in the communities should be priorities and issues that may have gone unnoticed otherwise. These issues will be addressed either by the modules or other resources. Our intention is to partner with a third party organization to develop a center where volunteers can receive training and farmers can have aid similar to Agrilife Extension programs. By choosing to address the issues perceived by the community at a level best understood, the training modules might have a greater and lasting impact.

Table 1: Initial Case Study for Farmers

\begin{tabular}{|c|c|}
\hline Case Study Questions & Responses \\
\hline \multicolumn{2}{|l|}{ Background Information } \\
\hline Age & A) 0-18 B) $19-30$ C) $31-40$ D) $41-50$ E) $51+$ \\
\hline Education level & $\begin{array}{l}\text { A) Elementary B) Middle School C) High school D) } \\
\text { College E) None }\end{array}$ \\
\hline How were you taught? & A) Parents B) Teachers C) Community D)Other \\
\hline Literacy Level & A) Below Basic B) Basic C)Intermediate D) Proficient \\
\hline Financial Status & $\begin{array}{l}\text { A) Upper class B) Middle class C) Lower class } \\
\text { D)Impoverished }\end{array}$ \\
\hline \multicolumn{2}{|l|}{ Household Information } \\
\hline $\begin{array}{c}\text { How many people currently live in your } \\
\text { home? }\end{array}$ & A) 1-2 B) 3-4 C) 5-6 D) $7+$ \\
\hline What is your role in the family? & $\begin{array}{l}\text { A)Main income provider B)Secondary Income } \\
\text { provider C)Caretaker/Household duties D) Dependent }\end{array}$ \\
\hline $\begin{array}{c}\text { If you are the main income provider, is } \\
\text { there a secondary provider? }\end{array}$ & A)Yes B)No \\
\hline Do you own the land you farm? & A)Yes B)No \\
\hline $\begin{array}{l}\text { What role do most women play in your } \\
\text { community? }\end{array}$ & $\begin{array}{l}\text { A)Main income provider B)Secondary Income } \\
\text { provider C)Caretaker/Household duties D) Dependent }\end{array}$ \\
\hline
\end{tabular}




\begin{tabular}{|c|c|}
\hline \multicolumn{2}{|l|}{ Farming } \\
\hline $\begin{array}{l}\text { What's your community's biggest } \\
\text { farming problem? }\end{array}$ & $\begin{array}{l}\text { A)Weather B) Resources C) Storage D)Harvesting } \\
\text { E)Other }\end{array}$ \\
\hline $\begin{array}{l}\text { What main aspect of your farming do } \\
\text { you want to improve? }\end{array}$ & $\begin{array}{l}\text { A)Planting B)Growing C)Harvesting D)Drying } \\
\text { E)Storing F)Selling }\end{array}$ \\
\hline Most popular crop to grow? & A)Wheat B)Maize C)Fruits/Vegetables D)Other \\
\hline Biggest problem with your crops? & $\begin{array}{l}\text { A)Weather B) Resources C) Storage D)Harvesting } \\
\text { E)Other }\end{array}$ \\
\hline $\begin{array}{l}\text { How much of your yearly harvest is lost } \\
\text { every year? }\end{array}$ & A) $0-5 \%$ B)6-15\% C) $16-30 \%$ D) $31-50 \%$ E) $51 \%+$ \\
\hline $\begin{array}{l}\text { What is the main cause of your harvest } \\
\text { losses? }\end{array}$ & $\begin{array}{l}\text { A)Drying B)Storage C)Molds D)Pests E)Can't sell } \\
\text { them }\end{array}$ \\
\hline \multicolumn{2}{|l|}{ Technologies } \\
\hline $\begin{array}{c}\text { When do you purchase farming } \\
\text { equipment? }\end{array}$ & $\begin{array}{l}\text { A)Off season B)Before planting C)Before harvesting } \\
\text { D)After harvesting }\end{array}$ \\
\hline $\begin{array}{l}\text { What practices/technologies do you use } \\
\text { to dry and store crops? }\end{array}$ & Fill in the blank \\
\hline How did you learn these practices? & Fill in the blank \\
\hline How do you store your crops? & $\begin{array}{l}\text { A)At home B)Collectively with the community C)Both } \\
\text { D)Other }\end{array}$ \\
\hline $\begin{array}{l}\text { Would you rather save more money } \\
\text { now or make more money long term? }\end{array}$ & A)Save money now B)More money long term \\
\hline \multicolumn{2}{|l|}{ Training Information } \\
\hline $\begin{array}{c}\text { Have you had past experience with a } \\
\text { harvest workshop? }\end{array}$ & A)Yes B) No \\
\hline If yes, what do you remember about it? & Fill in the blank \\
\hline If not, would you be interested? & A)Yes B)No \\
\hline $\begin{array}{l}\text { How much time would you have to } \\
\text { spare for a workshop? }\end{array}$ & $\begin{array}{l}\text { A)A few hours B)A day C)A few days D)A week } \\
\text { E)Other }\end{array}$ \\
\hline $\begin{array}{l}\text { What would you like the training to } \\
\text { look like? (circle all that apply) }\end{array}$ & A)Movie B)Pictures C)Oraly D)Real examples \\
\hline What time of year is best to come? & Fill in the blank \\
\hline
\end{tabular}


Module design

Once the case study has been evaluated, a series of modules is developed and edited in accordance with the collected response. The modules divide into two components. The first module will be the "Train-the-Trainer" module which will educate volunteers on how best to serve the community given their cultural, social, and agricultural backgrounds. The trainers will be well educated volunteers with a service and agriculture background. They would be recruited from organizations similar to the Texas A\&M AgriLife Extension service or the Peace Corps. This module is demonstrated in a prezi presentation and gives the volunteers a chance to accurately learn and understand where the women in this community are coming from and how best to serve their needs. This module is designed to be interactive with the audience and encourages critical thinking and self-evaluation. This style of teaching is shown to be the most efficient in teaching highly qualified individuals new information as well as how to properly relay what they are learning $[13,14]$. This will prepare the trainers to teach the end users as well as additional volunteers [15]. With the Prezi format, the module could be adaptable for use to train volunteers before they leave or act as transition between incoming and leaving volunteers at the location.

Tier two is the education module designated for the community members. This module will be presented by the educated volunteers over a predetermined length of time. At the end of the education session, the women farmers are asked to bring a member of their community with them to demonstrate what they have learned over the course of the modules in order to solidify their knowledge. This activity will also spread information to more members of the community. Once the entire two step system is complete, an evaluation of the community will take place after their first harvest cycle is complete in order to determine the modules' effectiveness (see Table 2). The assessment will gather updated information on specific measurable such as amount of maize produced and net profit. These values will be compared with the values measured before the training began in the initial case study of the community. A survey determining if there has been an increased utilization of PHL reducing technologies will be conducted as well comparing technologies used in the previous harvests to post-training. These studies are vital in determining the effectiveness of the education efforts and will aid in improving the modules and processes.

Table 2: Example Questions for the Post Harvest Evaluation 


\begin{tabular}{|c|l|}
\hline Did you purchase any PICS bags? & A)Yes B) No \\
\hline $\begin{array}{c}\text { If yes, did you utilize them this } \\
\text { harvest season? }\end{array}$ & A)Yes B) No \\
\hline $\begin{array}{c}\text { On a scale of 1-5 (5 being the most } \\
\text { effective) how helpful did you find } \\
\text { the training? }\end{array}$ & $\begin{array}{c}\text { A)1 B)2 C)3 } \\
\text { D) } 5\end{array}$ \\
\hline $\begin{array}{c}\text { Was your profit greater or less } \\
\text { than the previous year? }\end{array}$ & A)Greater B)Less \\
\hline $\begin{array}{c}\text { Would you recommend the training } \\
\text { to a }\end{array}$ & A)Yes B) No \\
fellowrer? & Fill in the blank \\
\hline $\begin{array}{c}\text { What can be done to improve } \\
\text { the trining? }\end{array}$ & \\
\hline
\end{tabular}

These are sample questions to show what the post harvest season evaluation will look like. Questions and length are subject to change as we perform additional evaluations throughout the process.

\section{Results}

The "train the trainer" presentation is divided into five sections as shown in Fig 1. The figures in this paper will serve as an overview for more in depth modules. These were deemed the best and most accurate ways to best educate the volunteers on how to achieve maximum impact.

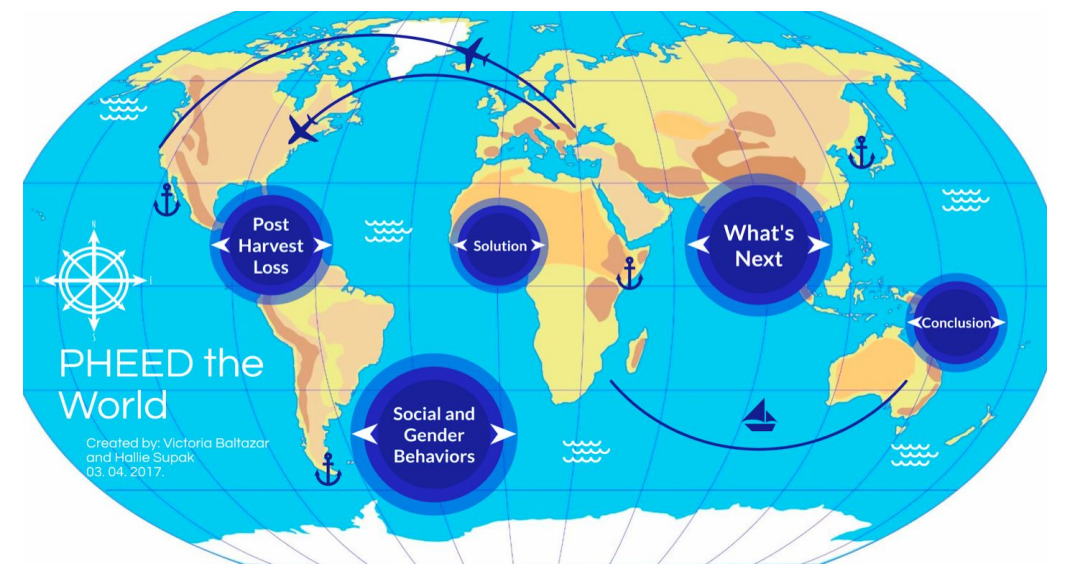

Figure 1. Concept Module to train volunteers using Prezi 


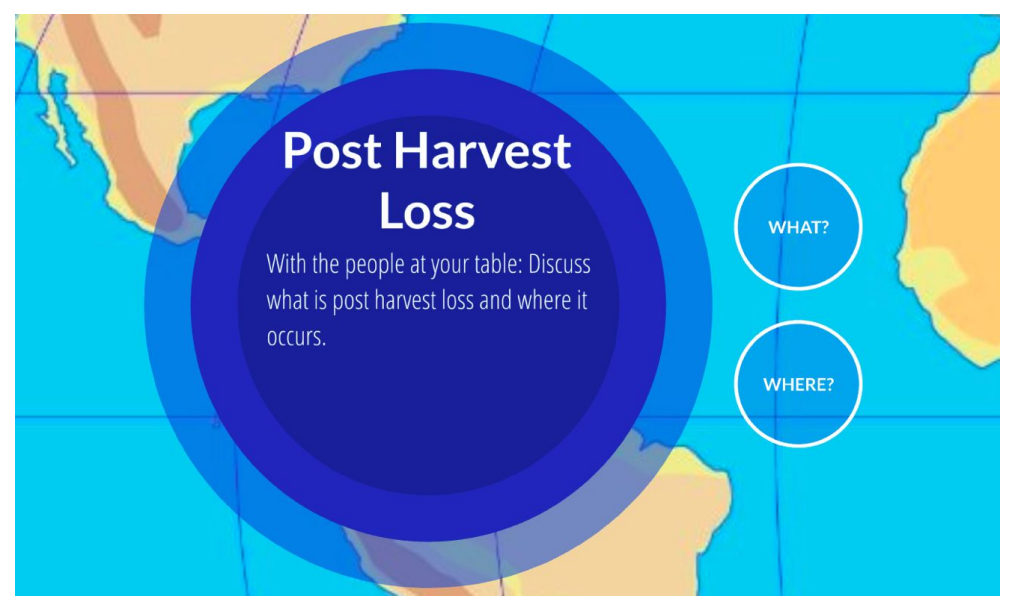

Figure 2. PHL section and subsections of volunteer module.

Post Harvest Loss: The first section covers all aspects of the post-harvest process. This section begins by engaging the audience with a discussion of what PHL is and where it occurs as shown in Fig. 2. Following the discussion, a definition and figures of global PHL published by FAO are presented. The volunteers are then taught the steps of the harvest process and what types of losses can occur at each step, such as pests during drying or mold growth during storage. This information was found during the background research. Following this, current PHL technologies and practices are presented and possible drawbacks are discussed. The module then goes on to the purpose of the training, transitioning to the next section to discuss where the volunteers will be working. Information regarding the target country is presented based on data from GHI, FAO, and any other national agencies.

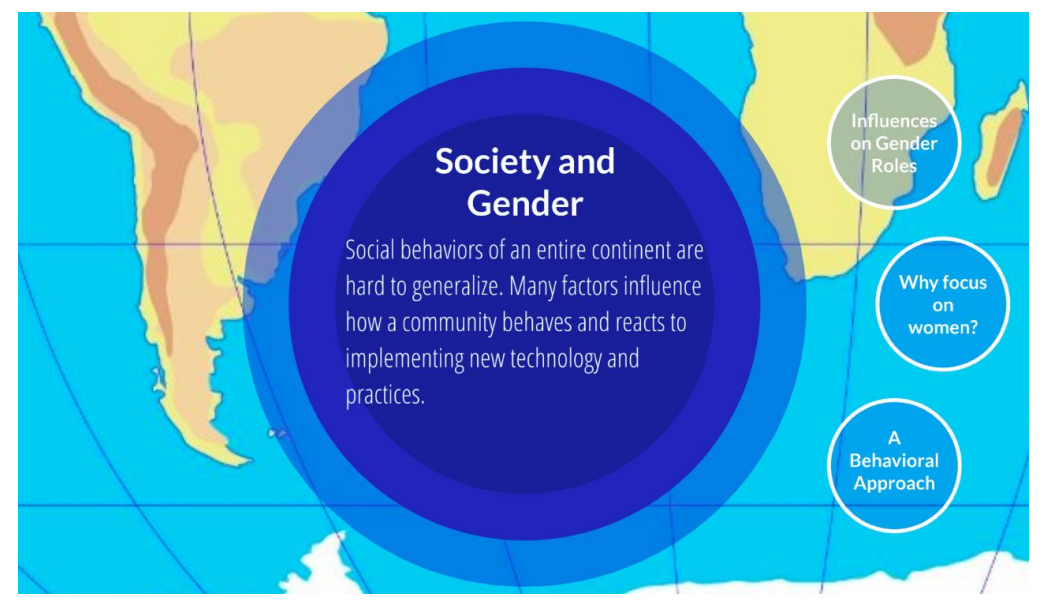

Figure 3. Society and Gender section of volunteer module.

Social and Gender Behaviors: This section is the main purpose of this module. By addressing gender and societal influence on the adoption of technology and practices, volunteers will have a 
richer background of understanding they can filter the information through. In the Influences of Gender Roles subsection as seen in Fig. 3, data from the background section of this paper is discussed. The audience is asked to think about different scenarios related to gender that might affect the success of a farm. Given the background information from the initial survey, the trainees will be taught ways to best engage with the women in the community. The next subsection explains that focusing our efforts to provide resources for women creates a chain reaction leading to reduced crop losses and an increase food security. The Behavioral Approach subsection presents the main idea that PHL technologies are not continually implemented due to a misalignment of resources, needs, and cultural norms. Here, cases found in the background section possible solutions are discussed.

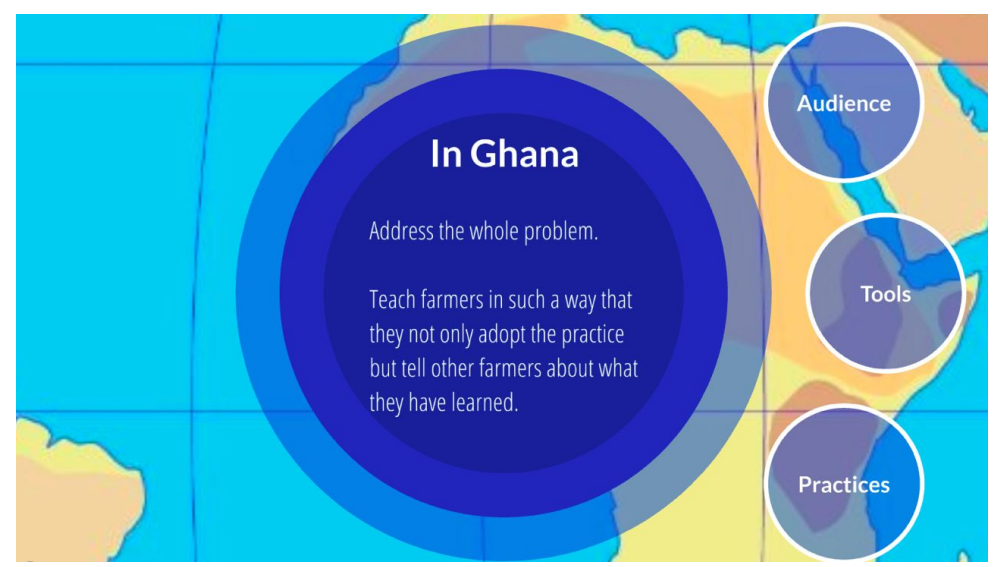

Figure 4. Solution section for volunteer module designed to be adaptable.

Solution: This section discusses the process through which the issue will be addressed as shown in Fig. 4. The results from the background and household sections will be presented in an Audience subsection. Under Tools, volunteers will be asked to reflect on this module and discuss the teaching strategies used to engage with the audience and increase memory retention. Any other resources available to volunteers such as translators or equipment can be listed here. Information on teaching strategies to be used in this program are under the Practices subsection. The solution section is made to be the adaptable portion of the module, that will change the most from case to case.

What's Next: In this section, volunteers are given time to practice teaching each other as if they were in the given community. Volunteers will be provided the materials for the farmer's module and must present the material with the strategies they have learned. They will then complete a self-evaluation of their progress through this module. If the module is being used to transition between volunteers, this section could be converted to discuss where the community is and provide contacts for the new volunteers. 
Conclusion: The final section is a review for the volunteers, to reiterate important points and discuss any confusion over the topics. Through review and repetition over the period of this module, these concepts will be better retrained and applied.

Once volunteers have completed the training module, they will be given a manual of the module used for the farmers. This manual will contain the topics covered in the module and exercises that may be useful to reinforce information.

Module concept for farmers

For the modules for the farmers, our research evaluation using published journals showed most losses occur in the drying and storage steps of the harvest process [8]. Therefore, the sections in this module will focus on best practices and available technology for those steps. Training modules for farmers on different topics, such as fertilizer, already exist. We are using these resources to help outline what information should be addressed and in what order. We also want to implement a mixture of tactile, visual, and auditory components to reach all types of learners across the language barrier.

The medium to present the modules would be best through video and interactive session with trained volunteers. From interviews with volunteers who have previously working with farmers in Sub-Saharan Africa, movies are impactful because they are uncommon within these rural communities. We plan to use resources such as Camtasia to create videos for the concept modules. Volunteer trainers will also have a manual to which they can reference important discussion points and exercises.

For the videos, they will be split essentially two parts: drying and storing with more emphasis on storage aspects. Studies have shown that if given too much information, the farmers are unable to recall most details after the trainings are complete [11]. For this purpose, only a select group of topics and technologies will be focused on. The drying portion of the module begins with highlighting the current drying practices and their faults. Drying maize on the traditional wooden platforms is inefficient and exposes the crop to insect infestation [11]. There will also be a focus on the problems of incomplete drying and how it leads to rotten cereals. After highlighting the problems, solutions for each issue will be explained in depth within the video as well as visual tactiles, such as improved storage technologies will be shown to further engrain proper technique. For example, using tarps for drying is the recommended method, so this process will be demonstrated and the participants will be given the opportunity to practice with the new technology. 
The same style of education derived for the drying process will be done to explain better storage systems. The current storage bags that are used are not completely air-tight which further leads to bug and moisture infestation. The video will be showing in-depth animations of these problems to further understand the issues at hand. The solution video will then show another animation highlighting the major benefits of using PICS bags and how their three layers keeps all unwanted elements out. A physical comparison of the two bags will be demonstrated, and the students will be able to use each firsthand to compare the differences in the storage bags. A simple bar graph of cost and profit benefits as well as a timeline will be shown in order to better visualize the farmers' harvest potential once they begin to use these new technologies. If available, a representative from a farmer's association will be present to discuss the benefits of joining. A video and description of the collective storage units will also be shown to further prove its benefits.

In order to combat the issue of not recalling a majority of the pertinent information learned during previous trainings, there will be two additional module aspects added to typical education sessions. On the last day of the off-season education session, the farmers will be asked to bring another member of their community to the training. This last day will be centered entirely on refreshing everyone on what they learned and giving the farmers a chance to demonstrate what they learned to their guest. This step will help to engrain the techniques and technologies into the students minds' as well as spread the knowledge to another member of the community. The second and final edition of the education modules provides a follow up course. The bulk of the training is done in the off-season because that is when farmers have the most time for activities outside of farming, but this causes forgetfulness and inconsistent use of the tools taught. A brief follow-up course being taught right before harvest season will serve as a refresher for all the information they had learned in the months prior and will help them prioritize these helpful strategies. Keeping it short and concise is necessary due to the busy time of year and will increase effectiveness and attendance.

\section{Citations}

[1] N. Scialabba, O. Jan, C. Tostivint, A. Turbe, C. O'Connor, P. Lavelle, A. Flammini, J. Hoogeveen,M. Iweins, F. Tubiello, L. Peiser, and C. Batello, "Food wastage footprint: Impact on natural resources," Food and Agriculture Organization of the United Nations, 2013. [Online]. Available: http://www.fao.org/docrep/018/i3347e/i3347e.pdf [Accessed 20 January 2019] [2] D. Kumar and P. Kalita, "Reducing postharvest losses during storage of grain crops to strengthen food security in developing countries," Foods, vol. 6, no. 1, January 2017. [Online]. Available: The National Center for Biotechnology Information, https://www.ncbi.nlm.nih.gov/ [Accessed 10 June 2018]. 
[3] K. von Grebmer, J. Bernstein, F. Patterson, A. Sonntag, L. Klaus, J. Fahlbusch, Ol. Towey, C. Foley, S. Gitter, K. Ekstrom, H. Fritschel and L. Hammond, Global Hunger Index: Forced Mitigation and Hunger. Dublin/Bonn: GHI, October 2018.

[4] Food and Agriculture Organization of the United Nations, World Food and Agriculture Statistical Pocketbook. Rome: FAO, 2018.

[5] B. Darfour and K. Rosentrater, "Agricultural and food security in Ghana," in 2016 ASABE International Meeting, ASABE 2016, Orlando, FL, July 17-20, 2016. [Online]. Available: ASABE elibrary, http://elibrary.asabe.org/abstract.asp?aid=47207\&t=3\&redir=\&redirType= [Accessed 4 September 2018].

[6] C. Doss, Twenty Five Years of Research on Women Farmers in Africa: Lessons and Implications for Agricultural Research Institutions; with annotated bibliography. Mexico: CIMMYT, 1999.

[7] B. Darfour and K. Rosentrater, "Maize in Ghana: An overview of cultivation to processing," in ASABE Annual International Meeting, 2016 ASABE 2016, Orlando, FL, USA, July 17-20, 2016. [Online]. Available: ASABE elibrary, https://elibrary.asabe.org/abstract.asp?aid=47204 [Accessed 5 September 2018].

[8] T. Abdoulaye, J. Ainembabazi, C. Alexander, D. Baributsa, D. Kadjo, B. Moussa, O. Omotilewa, J. Ricker-Gilbert, and F. Shiferaw, "Postharvest loss of maize and grain legumes in sub-saharan Africa: Insights from household survey data in seven countries," Purdue Extension: Agricultural Economics, EC - 807- W, April 2016. [Online]. Available:

https://www.extension.purdue.edu/extmedia/EC/EC-807-W.pdf [Accessed 11 June 2018]

[9] F. Dowell and C. Dowell, "Reducing grain storage losses in developing countries," Quality Assurance and Safety of Crops \& Foods, vol. 9, no. 1, p. 93-100, June 2016. [Online]. Available: Wageningen Academic Publishers, https://www.wageningenacademic.com/ [Accessed 10 June 2018].

[10] D. Bbosa, T. Brumm, C. Bern, K. Rosentrater, and D. Raman, "Evaluation of hermetic maize storage in $208 \mathrm{~L}$ steel barrels for smallholder farmers," Transactions of the ASABE, vol. 60, no. 3, p. 981-7. [Online]. Available: Iowa State University Digital Repository, https://lib.dr.iastate.edu/abe_eng_pubs/818/[Accessed 14 June 2018]

[11] J. Kaminski, L. Christiaensen, "Post harvest losses in sub-saharan Africa: What do farmers say," FAO. [Online]. Available: World Bank, http://documents.worldbank.org/curated/en/home [Accessed 4 September 2018]

[12] A. Daminger, S. Datta, and D. Guichon, REDUCING POST-HARVEST LOSS: A Behavioral Approach. [Online]. New York: ideas42, 2012. Available at: https://www.ideas42.org/wp-content/uploads/2016/10/PostHarvestLoss_FINAL.pdf [Accessed 10 June 2018].

[13] K. Alade, "Training of trainers 2018 - Association of Organic Agriculture Practitioners of Nigeria", Association of Organic Agriculture Practitioners of Nigeria, 2018. [Online]. Available: https://noanigeria.net/training-of-trainers-2018/?v=7516fd43adaa. [Accessed January 2019] 
[14] P. Gleeson, "What is the train the trainer model?", Work.chron.com, 2017. [Online]. Available: https://work.chron.com/train-trainer-model-5463.html. [Accessed January 2019] [15] R. Hodges and T. Stathers, Training Manual for Improving Grain Postharvest Handling and Storage. UK: Food and Markets Department, Natural Resources Institute, 2012. [Online]. Available:

https://documents.wfp.org/stellent/groups/public/documents/reports/wfp250916.pdf?_ga=2.2182 2072.2136693818.1528982238-16100878.1526336261. [Accessed: January 2019] 